\title{
Dynamic Asset Allocation under Stochastic Volatility - Theory and Practice
}

\author{
Chung-Gee Lin $^{1}$ \\ ${ }^{1}$ Department of Business Mathematics \\ Soochow University \\ 56, Kuei-Yang Street, Section 1, Taipei City 100, Taiwan. \\ Tel: +886-2-2311-1531 ext. 3629. \\ Fax: +886-2-2381-2510. \\ E-mail:cglin@bmath.scu.edu.tw
}

\begin{abstract}
This study develops inter-temporal dynamic asset allocation with stochastic volatility (DAASV) models. The DAASV models integrate the stochastic volatility feature inherent in asset returns into the allocation procedure. By applying the DAASV, an investor can more efficiently diversify the unsystematic risks, so as to achieve better performance. We demonstrate that the DAASV models dominate the traditional meanvariance portfolio models by using Taiwan equity market empirical data. Finally, we show that under the consideration of trade-off between transaction costs and rebalancing timing, an optimal asset allocation rebalancing frequency can be derived.
\end{abstract}

Keywords: asset allocation, stochastic volatility, transaction cost.

\section{Introduction}

Asset allocation is in itself a practical issue, it has long been a topic of great interest for practitioners and academics, especially for the institutional investors who routinely possess a large number of assets. Markowitz (1952) pioneered developing the meanvariance (MV) optimization framework for portfolio selection. The MV model is assumed to be a suitable technique to obtain efficient investments in modern portfolio theory. However, the original MV model was built under a one-period framework; moreover, many empirical studies have shown that the most important assumption - fixed mean and volatility of asset return- in the MV framework of Markowitz (1952) is not supported. ${ }^{1}$ The over-simplified one-

\footnotetext{
${ }^{1}$ Blattberg and Gonedes (1974), Castanias (1979), and Christie (1982) showed that the variances change over time. Hull and White (1987), Johnson and Shanno (1987), Scott (1987), Wiggins (1987), and Stein and Stein (1991), to name a few, developing stochastic volatility option pricing schemes to conquer the constant volatility
}

period and constant mean and volatility assumption of asset return inherent in the MV model results in its failure for practical asset allocation application.

This study develops inter-temporal dynamic asset allocation with stochastic volatility (DAASV) models, which integrate different stochastic volatility features of assets into the allocation procedure. The DAASV models relax the limitation in the traditional MV model such as the parameters of asset return are symmetrically distributed. Consequently, investors can more efficiently diversify the unsystematic risks by applying the DAASV, so as to achieve better investment performance.

To capture the practical stochastic volatility features of asset returns, we propose two DAASV models. The first is the DAASV-G model, which allows the volatility of asset return to follow a geometric Brownian motion. The second is the DAASV-M model, which allows the volatility of asset return to follow a CIR (Cox, Ingersoll, and Ross, 1985) meanreverting stochastic process. However, as the constant volatility assumption removed, an analytic solution to the optimal asset allocation weights is no longer exists. By applying the Monte Carlo simulation technique together with a regional enumeration searching, we can effectively derive the optimal solution for DAASV models.

The rest of this paper is organized as follows. Section 2 demonstrates the basic mean-variance portfolio framework and the DAASV models. Section 3 presents the empirical analyses of different asset allocation models. We demonstrate that the DAASV

problem. Few studies have examined the asset allocation problem by considering the first two moments of asset returns are varying over time. However, these studies only explore the case of one risky asset. The interested readers can refer to Gomes (2002), and Han (2004) 
models dominate the traditional mean-variance portfolio models by using Taiwan equity market empirical data. Section 4 exploits the effect of transaction cost to asset allocation. We also prove in this section that under the consideration of trade-off between transaction costs and rebalancing timing, an optimal asset allocation rebalancing frequency can be derived. We finally draw conclusions in section 5 .

\section{The models}

\subsection{The mean-variance framework}

Markowitz (1952) pioneered developed a meanvariance (MV) efficient portfolio selection model. The MV model derive the weight of each candidate asset by minimize the volatility of the portfolio subject to a predetermined required return. The formulation is as follows

$$
\begin{aligned}
& \text { Min } o_{\mathrm{Pt}}^{2}=\sum_{\mathrm{i}=1}^{\mathrm{n}} \sum_{\mathrm{j}=1}^{\mathrm{n}} \mathrm{x}_{\mathrm{it}} \mathrm{x}_{\mathrm{jt}} \hat{o}_{\mathrm{ijt}} \\
& \text { S.T. } \quad \sum_{\mathrm{i}=1}^{\mathrm{n}} \mathrm{x}_{\mathrm{it}} \mathrm{E}\left(\mathrm{r}_{\mathrm{it}}\right)=\mathrm{R}_{\mathrm{t}}^{*}
\end{aligned}
$$

where $\sigma_{\mathrm{Pt}}^{2}$ is the total variance of portfolio with $n$ candidate assets at time $\mathrm{t} ; \sigma_{\mathrm{ijt}}$ is the covariance of asset $\mathrm{i}$ and $\mathrm{j} ; \mathrm{E}\left(\mathrm{r}_{\mathrm{it}}\right)$ is the expected return of asset $\mathrm{i}$ at time $\mathrm{t} ; \mathrm{R}_{\mathrm{t}}{ }^{*}$ is the predetermined required return for investing the portfolio at time $\mathrm{t} ; \mathrm{X}_{\mathrm{it}}$ is the proportion invested into asset $\mathrm{i}$ at time $\mathrm{t}$, which is the solution to an asset allocation we are going to solve. We allow the investor to short sell assets, the restriction on the proportion of each asset $\mathrm{i}$ at time $\mathrm{t}$ is $-1 \leq \mathrm{x}_{\mathrm{it}} \leq 1$.

Assume the investment horizon is T, say 2 years, and an investor rebalance his/her portfolio every 6 months (rebalance frequency $\Delta \mathrm{t}=0.5$ years), then the investor will adjust the portfolio $4(=2 / 0.5)$ times in the whole period of 2 years horizon. If $\mathrm{T}=\Delta \mathrm{t}$, then the investor adopts the so called buy-and-hold strategy, since he/she only adjust the portfolio once at the beginning of investment.

\subsection{The DAASV models}

Under the MV framework of Markowitz (1952), we only need to know the first two moments of asset returns so as to find the solution of optimal asset allocation of a portfolio. However, to integrate the practical stochastic volatility features inherent in assets into the asset allocation procedure, we develop the DAASV models as follows.

$$
\begin{gathered}
\frac{\mathrm{dS}_{\mathrm{it}}}{\mathrm{S}_{\mathrm{it}}}=\mathrm{i}_{\mathrm{it}} \mathrm{dt}+\mathrm{o}_{\mathrm{it}} \mathrm{d} \mathrm{Z}_{\mathrm{it}} \\
\text { dó }{ }_{\mathrm{it}}=\mathrm{a}_{\mathrm{it}} \hat{o}_{\mathrm{it}} \mathrm{dt}+\mathrm{c}_{\mathrm{it}} \mathrm{o}_{\mathrm{it}} \mathrm{d} \mathrm{W}_{\mathrm{it}} \\
\text { dó }{ }_{\mathrm{it}}=\mathrm{a}_{\mathrm{it}}\left(\mathrm{b}_{\mathrm{it}}-\mathrm{o}_{\mathrm{it}}\right) \mathrm{dt}+\hat{\imath}_{\mathrm{it}} \sqrt{\mathrm{o}_{\mathrm{it}}} \mathrm{dW} \mathrm{W}_{\mathrm{it}}
\end{gathered}
$$

where $\mathrm{S}_{\mathrm{it}}$ is the market price of candidate asset $\mathrm{i}$ at time $\mathrm{t} ; \mathrm{i}_{\text {it }}$ is the drift rate of asset $\mathrm{i}$ at time $\mathrm{t} ; \sigma_{i t}$ is the volatility rate of asset $i$ at time $t$; $a_{i t}$ is the drift rate of volatility of asset $i$ at time $t$; $c_{i t}$ is the volatility rate of volatility of asset $i$ at time $t$ when the volatility of asset return follows a geometric Brownian motion; $\mathrm{a}_{\mathrm{it}}$ is the convergence speed parameter of volatility of asset $i$ at time $t ; b_{i t}$ is the long-term mean of volatility of asset $i$ at time $t ; c_{i t}$ is the volatility rate of volatility of asset $i$ at time $t ; \hat{\mathbf{1}}_{\text {it }}$ is the volatility rate of volatility of asset $i$ at time $t$ when the volatility of asset return follows a geometric Brownian motion; $\mathrm{dZ}_{\mathrm{it}}$ and $\mathrm{dW}_{\text {it }}$ are standard Wiener processes.

Equation (2) is the stochastic process of assets, which follows the geometric Brownian motion. As the volatility of asset return follows equation (3), the geometric Brownian motion, we call it the DAASV-G model. If the volatility of asset return follows equation (4), the CIR stochastic process, we call it the DAASV-M model.

\subsection{Performance evaluation criteria}

To gauge the performance of different asset allocation models, we apply the Sharpe ratio as the performance evaluation measure.

$$
\frac{\tilde{1}_{\mathrm{Pt}}-r_{\mathrm{ft}}}{\tilde{\mathrm{O}}_{\mathrm{Pt}}}
$$

where $\tilde{\mathbf{1}}_{\mathrm{Pt}}=\mathrm{E}\left(\sum_{\mathrm{i}=1}^{\mathrm{n}} \mathrm{x}_{\mathrm{it}} \mathrm{r}_{\mathrm{it}}\right), \tilde{\mathrm{o}}_{\mathrm{Pt}}=\sum_{\mathrm{i}=1}^{\mathrm{n}} \sum_{\mathrm{j}=1}^{\mathrm{n}}\left(\mathrm{x}_{\mathrm{it}} \mathrm{X}_{\mathrm{jt}} \boldsymbol{o}_{\mathrm{ijt}}\right), \mathrm{r}_{\mathrm{ft}}$ is the risk-free rate of return at time $t$. The economic meaning of Sharpe ratio is the excess return over riskfree rate of return per unit portfolio risk (volatility). A portfolio performs better than others as it has a larger Sharpe ratio than the others.

\section{Empirical analyses}

To test the performance of different asset allocation models, we use the Taiwan equity market data for empirical analyses. The date set is from TEJ, the leading financial data bank of Taiwan, and the 
empirical analyses period is from March 10, 2004 to March 10, 2006. The candidate assets include 50 stocks, which are from the top 10 largest firm value companies of 5 industries, showed in Table 1.

\section{【Insert Table 1 about here】}

From Table 2, under the scenario of no transaction cost, we know that the DAASV-M consistently performs best among the asset allocation models for different rebalancing frequencies, than is the DAASVG.

\section{【Insert Table 2 about here】}

It is apparently that the DAASV-M, stochastic volatility with mean-reverting feature can capture the real asset stochastic processes better than the other asset allocation model. However, since all the DAASV models dominate the original MV model proposed by Markowitz (1952), we can conclude that it is necessary to incorporate the stochastic volatility characteristics of asset return so as to improve the investment performance.

\section{The transaction cost effects and optimal rebalancing frequency}

\subsection{The transaction cost effects}

Transaction cost is critical to the practical asset allocation procedure. Theoretically, as the rebalancing frequency increases the performance of asset allocation will increase as well. However, the statement mentioned above will come into existence only in the world of no transaction cost. As we consider the transaction cost of rebalancing portfolio, more adjustment to the portfolio, more transaction fee and tax the investor has pay to the stock broker and the government. By considering the trade-off of the rebalancing and transaction cost effects, we infer that there must be an optimal rebalancing frequency exists for the dynamic asset allocation model.

\section{【Insert Table 3 about here】}

From Table 3 we can tell that the result is similar to Table 2, the DAASV-M consistently performs best among the asset allocation models for different rebalancing frequencies, than is the DAASV-G. However, the Sharpe ratios are systematically smaller than those in Table2. One thing worth noticing is that the Sharpe ratios no longer increase as the rebalancing frequencies rise.

\subsection{Optimal rebalancing frequencies}

We infer from last section that there must be optimal rebalancing frequencies exist for different asset allocation models, as we consider the transaction cost and adjustment effects. From the result of Figures 1 and 2, we prove that my hypothesis is hold. As we neglect the effects of transaction cost, from Figure 1 we see that the performance of every asset allocation models increase when the rebalancing frequencies rise. However, as we take into account of the trade-off between transaction costs and rebalancing timing, we can see from Figure 2, optimal asset allocation rebalancing frequencies do exist in all the three asset allocation models.

【Insert Figures 1 and 2 about here】

\section{Conclusions}

We provide the DAASV models which can effectively integrate the practical stochastic volatility features in asset returns. By applying DAASV, we prove in this study that an investor can consistently acquire a better investment performance than the traditional meanvariance portfolio model. Among the DAASV models, the one with mean-reverting stochastic volatility feature, the DAASV-M model, is more suitable for the Taiwan equity market.

On the other hand, we prove that optimal rebalancing frequencies do exist for all kind of asset allocation models. By applying our procedure, investors can find the optimal rebalancing frequency for their asset allocation so as to achieve a better investment performance.

\section{References}

[1] Blattberg, R.C., and N.J. Gonedes, "A Comparison of the Stable and Student Distributions as Staticstical Models for Stock Prices," Journal of Business, 47, 244-280, 1974.

[2] Castanias, R.P., "Macroinformation and the Variability of Stock Market Prices," Journal of Finance, 34, 439-450, 1979.

[3] Christie, A.A., "The Stochastic Behavior of Common Stock Variance: Value, Leverage and Interest Rate Effects," Journal of Financial Economics, 6, 213-234, 1982.

[4] Cox, J.C., J.E. Ingersoll, and S.A. Ross, "A Theory of the Term Structure of Interest Rates," Econometrica, 53, 385-407, 1985.

[5] Gomes, F., "Exploiting Short-Run Predictability," working paper, London Business School, 2002.

[6] Han, Y., "Can An Investor Profit from Return Predictability in Real Time?" working paper, Tulane University, 2004.

[7] Hull, J., and A. White, "The Pricing of Options an Assets with Stochastic Volatilities," Journal of Financial, 42, 281-300, 1987. 
[8] Johnson, H. and D. Shanno, "Option Pricing When the Variance Is Changing," Journal of Financial and Quantitative Analysis, 22, 143-151, 1987.

[9] Markowitz, H.M., "Portfolio selection," 52(7), 22, 1-16, 1952.

[10] Scott, L., "Option Pricing When the Variance Changes Randomly: Theory, Estimation and An Application," Journal of Financial and Quantitative Analysis, 26, 419-438, 1987.

[11] Stein, E., and J. Stein, "Stock Price Distributions with Stochastic Volatility: An Analytic Approach," Review of Financial Studies, 4, 727-752, 1991.

[12] Wiggins, J., "Options Values under Stochastic Volatility: Theory and Empirical Estimates," Journal of Financial Economic, 19, 351-372, 1987.

\begin{tabular}{|c|c|c|c|c|}
\hline \multicolumn{5}{|c|}{ Table 1 } \\
\hline $\begin{array}{c}\text { The candidate stock number codes of Taiwan equity market } \\
\text { industry }\end{array}$ & $\begin{array}{c}\text { Food } \\
\text { industry }\end{array}$ & $\begin{array}{c}\text { Plastics } \\
\text { industry }\end{array}$ & $\begin{array}{c}\text { Electrical } \\
\text { industry }\end{array}$ & $\begin{array}{c}\text { Traditional } \\
\text { industry }\end{array}$ \\
\hline 2881 & 1201 & 1301 & 2303 & 1402 \\
\hline 2882 & 1216 & 1303 & 2330 & 1440 \\
\hline 2883 & 1203 & 1304 & 2357 & 1409 \\
\hline 2886 & 1210 & 1308 & 2376 & 1408 \\
\hline 2887 & 1217 & 1309 & 2382 & 2501 \\
\hline 2888 & 1218 & 1310 & 2409 & 2511 \\
\hline 2891 & 1215 & 1312 & 2412 & 2526 \\
\hline 5820 & 1207 & 1314 & 2454 & 2002 \\
\hline 2825 & 1229 & 1326 & 3009 & 5007 \\
\hline 2851 & 1234 & 6505 & 5387 & 2006 \\
\hline $\begin{array}{l}\text { The date set is from TEJ, the leading financial data bank of Taiwan, } \\
\text { and the empirical analyses period is from March 10, 2004 to March } \\
10,2006 .\end{array}$ The candidate assets include 50 stocks, which are from the \\
top 10 largest firm value companies of 5 industries. \\
\hline
\end{tabular}

Table 2

The Sharpe rations performance of different asset allocation models without transaction cost

\begin{tabular}{|c|c|c|c|}
\hline & MV & DAASV-G & DAASV-M \\
\hline BH & 5.2129 & 6.5449 & 6.8334 \\
\hline $\begin{array}{c}\text { Rebalancing 2 } \\
\text { times }\end{array}$ & 5.3357 & 6.5721 & 6.9689 \\
\hline $\begin{array}{c}\text { Rebalancing 4 } \\
\text { times }\end{array}$ & 5.5306 & 6.5966 & 7.0736 \\
\hline $\begin{array}{c}\text { Rebalancing 8 } \\
\text { times }\end{array}$ & 6.3180 & 6.7494 & 7.7077 \\
\hline $\begin{array}{c}\text { Rebalancing } \\
24 \text { times }\end{array}$ & 6.5605 & 6.6801 & 7.7509 \\
\hline 1. The invest & & \\
\hline
\end{tabular}

1. The investment horizon is 2 years.

2. The required return $\mathrm{R}_{\mathrm{t}}{ }^{*}=0.03$.

3. BH represents the buy-and-hold strategy.

4. Rebalancing 2 times means the investor adjust his/her portfolio once a year, at the beginning of investment and at the end of fist year.

5. Rebalancing 4 times means the investor adjust his/her portfolio once every half years.

6. Rebalancing 8 times means the investor adjust his/her portfolio once every 3 months.

7. Rebalancing 24 times means the investor adjust his/her portfolio once every month.

8. We simulate the daily return with 10,000 paths each day for each asset and repeat 100 trials. The Sharpe ratios reported in this table are the mean values of simulations.

\begin{tabular}{|c|c|c|c|}
\hline \multicolumn{4}{|c|}{ Table 3 } \\
The Sharpe rations performance of different asset allocation \\
models with transaction cost
\end{tabular}

The settings are as Table 2

Figure 1

The Sharpe ratios of different asset allocation models without transaction cost

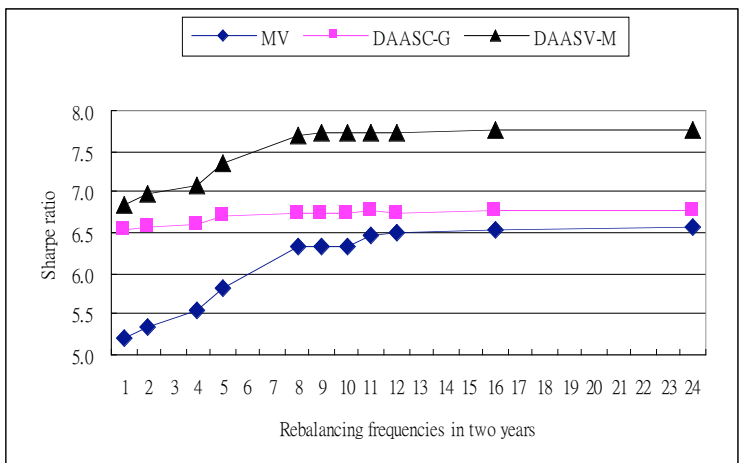

Figure 2

The Sharpe ratios of different asset allocation models with transaction cost

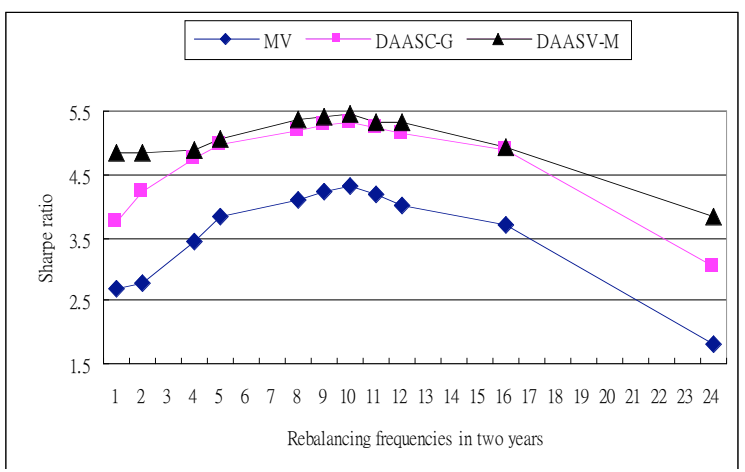

